\title{
Prevalence of Olfactory Dysfuntion in SARS-COV-2 Positive Patients
}

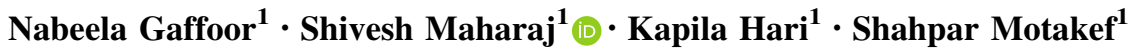

Received: 3 August 2021/ Accepted: 19 October 2021/Published online: 28 October 2021

(C) Association of Otolaryngologists of India 2021

\begin{abstract}
Severe acute respiratory syndrome coronavirus 2 (SARS-COV-2) is associated with chemosensory symptoms including olfactory dysfunction and dysgeusia. Multiple studies have reported differing prevalence rates of symptoms and recovery rates depending on geographic location. The purpose of the study was to determine the prevalence and features of Covid19 olfactory dysfunction in a developing nation. We conducted a prospective study at a tertiary, high-volume centre in South Africa, to determine the prevalence of olfactory dysfunction in SARS-COV-2 positive patients. The average recovery time of the olfactory dysfunction was also evaluated. The study included patients diagnosed with SARS-COV-2 infection between November 2020 and January 2021. Patients were recruited to participate in a survey which assessed demographic data, date of diagnosis, initial symptoms, presence and recovery time of olfactory dysfunction symptoms. A total of 86 patients with olfactory dysfunction were included and followed up telephonically over 6 weeks in 2 week intervals to determine recovery time. There was a prevalence rate of $40.7 \%$ of olfactory dysfunction in patients in our study. A higher proportion of patients with olfactory dysfunction had fever compared to those without and this was a significant finding in our study population. The overall median recovery time in our study was 7 days. Prevalence of olfactory dysfunction in our population is in keeping with European studies and most patients recover their sense of smell within a week.
\end{abstract}

Shivesh Maharaj

Shivesh.maharaj@wits.ac.za

1 School of Clinical Medicine, Faculty of Health Sciences, University of the Witwatersrand, Johannesburg, South Africa
Keywords SARS-Cov-2 · Covid-19 .

Olfactory dysfunction · Prevalence · Recovery

\section{Introduction}

Severe acute respiratory syndrome coronavirus 2 (SARSCOV-2), colloquially known as COVID-19, was first reported in Wuhan, China in December 2019. The World Health Organisation (WHO) declared COVID-19 a global pandemic on the eleventh of March 2020 [1]. In South Africa the first infection was detected on the 5th March 2020 and by the 8th July 2020 Gauteng had become the epi-centre of the country, accounting for $33.4 \%$ of all cases $[2,3]$

The most common symptoms associated with COVID19 include fever, cough, shortness of breath and generalized symptoms such as fatigue and myalgias.

Multiple studies have shown an association between COVID-19 and chemosensory symptoms such as olfactory dysfunction and dysgeusia $[4,5]$.

Olfactory dysfunction includes a complete loss of smell (anosmia); decreased sense of smell (hyposmia) or a distorted sense of smell (dysosmia). It can occur either in isolation or in the presence of other symptoms [6].

The cause of olfactory dysfunction caused by SARSCoV-2 has not been fully elucidated. Proposed hypotheses include damage to the nasal mucosal epithelium, as one theory, and the neurotropic nature of coronaviruses which enable them to affect the olfactory neurons directly, as another theory. SARS-CoV-2 is able to enter epithelial cells by directly binding to angiotensin-converting enzyme 2 (ACE2) on the cell surface. Significantly, the potential site of injury determines recovery where neuronal injury takes longer to recover [7]. 
Recognition of olfactory dysfunction by members of the public and the significance thereof by healthcare practitioners may assist in future earlier detection of infected individuals, as well as the use of proper personal protective equipment, thereby decreasing the spread of the virus [5].

In a recent systematic review, the pooled prevalence of olfactory dysfunction was 47\% [7]. Mullol et al. showed a wide regional variability, unfortunately there were no relevant studies conducted in Africa in this review [8].

We conducted a study to determine the prevalence of olfactory dysfunction in our setting (Chris Hani Baragwanath Academic Hospital, a tertiary teaching hospital in Johannesburg, South Africa).

\section{Literature Review}

Since the SARS-COV-2 outbreak, there have been different studies around the world to determine the association between olfactory dysfunction and SARS-COV-2.

Olfactory dysfunction is shown to be a useful tool to hold high suspicion of SARS-COV-2 infection in patients.

In a study by Zayet et al., two groups with symptoms were compared; a SARS-COV-2 positive and negative group, respectively. Anosmia occurred in $60 \%$ of the patients who tested positive versus $18 \%$ in those that tested negative. This study determined that anosmia as a positive predictive value of SARS-COV-2, is $77 \%$ and the PPV of anosmia in combination with taste dysfunction is higher, at $83 \%$. The specificity of anosmia was $85 \%$ and sensitivity $63 \%$ [9]. In another study done in California of over 200 patients, anosmia was found to be 10 times more common in SARS-COV-2 positive, then SARS-COV-2 negative, patients with flu like symptoms [10]. In a study by Vaira et al., $73.6 \%$ of SARS-COV-2 positive patients had olfactory and gustatory dysfunction [11].

The SARS-COV-2 olfactory related symptoms seem less prevalent in the Asian population as compared to the European population [5]. Liechen et al. showed in a European study that $85.6 \%$ of confirmed positive patients reported anosmia [12].

Kaye et al. reported $73 \%$ in a US study [13]. In a Korean study, 3191 patients were evaluated and approximately $15 \%$ had anosmia as a symptom [14]. In a review by ElAnwar et al., 11 studies were analysed; 8 out of 11 were from Asian countries and none reported smell symptoms. The only studies that reported olfactory symptoms were by an Italian study (Vaira et al.) and a study in Switzerland (Speth et al.) [15]. A study in India showed a low prevalence of $10.7 \%$ of OD [16].

Possible explanations may be that there was lack of awareness in early studies in these populations or nasal symptoms were under-reported [17]. Another explanation may be that the Asian population actually exhibited less nasal symptoms. It is possible that there may be different frequencies of variant ACE2 entry proteins in different populations [18, 19].

Recovery of SARS-COV-2 related anosmia is important to study, as it can be a disturbing symptom especially in the elderly, as it affects quality of life and can lead to depression, loss of appetite and weight loss [20]. Patients have been found to recover quickly, majority within 9 days and 14 days $[10,12]$. In a survey of 382 patients, recovery plateaus after 2 weeks [21]. A quick recovery suggests the virus targets neural epithelium as opposed to neuronal cells themselves [10]. In the study done in California $10 \%$ did not have resolution of anosmia however $82 \%$ were evaluated at only 2 weeks post infection [10]. It is possible that their anosmia may have resolved at a later stage.

Vaira et al. showed that $66 \%$ of patients had reported recovery of anosmia, however, an objective correlation shows that $80 \%$ of them still had hyposmia [11]. Subjective studies may under-report anosmia and over-report recovery.

\section{Aim}

The primary objective of this study is to determine the prevalence of olfactory dysfunction in SARS-COV-2 positive patients in one centre. The secondary objective is to determine the average recovery time of the olfactory dysfunction.

\section{Methods}

\section{Study Population}

This study included 101 diagnosed SARS-COV-2 positive patients discharged from designated" wards at Chris Hani Baragwanath Academic Hospital between November 2020 and January 2021. Patients were invited to participate in a survey.

The survey included the patients' demographic data, date of diagnosis, initial symptoms, presence and recovery time of olfactory dysfunction symptoms. Patients with olfactory dysfunction at the time of the survey were followed up telephonically over 6 weeks, in 2 week intervals to determine recovery time.

Participation was strictly voluntary and informed consent was obtained.

\section{Study Sample}

Sample sized predicted using the formula for prevalence below is 40 , where the confidence interval $\mathrm{Z}$ is $95 \%$, 
predicative prevalence is $60 \%$ (based on other studies [10] and margin of error is $1 / 4$.

$n=\frac{Z_{2} a / 2 P(1-P)}{d_{2}}$

However due to variability in other similar studies where prevalence is $33 \%$ and sample size would therefore be 133 , we decided on a study sample of 100 patients as this will attain reliable results and is feasible for a single researcher.

Inclusion criteria for patients:

Age $>18$ yrs.

- Laboratory confirmed SARS-COV-2 PCR on nasopharyngeal swabs.

\section{Exclusion criteria:}

- Medical diagnosis of allergic rhinitis made by a clinician.

- Ventilated patients during this hospital stay.

- Previous surgery, trauma or radiation to nasal or oral cavity.

- Olfactory symptoms before the current illness.

We also examined the effect of age, sex, use of certain medication on the prevalence of olfactory dysfunction.

Ethics was approved by Wits Research ethics committee (ref R14/49) and permission to conduct the study was provided by Chris Hani Baragwanath medical advisory committee.

\section{Data Extraction and Analysis}

Categorical variables were described using frequencies and proportions. Pearson's chi squared test was used to compare proportions or Fisher's exact test where data was sparse $(<5$ observations). Continuous variables were described using medians and the interquartile range. The Wilcoxon rank sum test was used to compare median values of continuous variables by sex while the KruskallWallis test compared median values by age group. Analyses were done in Stata 14, and statistical significance was set at $5 \%$.

\section{Results}

One hundred and one patients, testing positive for SARSCOV2, were recruited for the study. Fifteen were excluded (previous history of olfactory dysfunction, ICU admission during current admission(proxy for ventilation), medical history of rhinitis, previous surgery, trauma or radiation to nasal or oral cavity.)

A total of 86 patients were included in the study. There were $53(62 \%)$ males and $33(38 \%)$ females. There were 83 (97\%) black African patients.

From a sample of 86 patients admitted at a tertiary hospital with SARS-COV-2, 35 presented with olfactory dysfunction (OD), representing a prevalence of $40.7 \%$ (Table 1). The only clinical characteristic that was significant between patients with OD and those without was the presence of fever i.e. a higher proportion of patients with olfactory dysfunction had fever compared to those without ( $p$ value $=0.039)$. The overall median age was 48.5 years (IQR: 36.0-60.0) and median ages were similar between the 2 groups. $(p$ value $=0.107)$.

A significantly higher proportion of females were on treatment for hypertension and diabetes compared to males ( $p$ values were 0.018 and 0.037 respectively).

Among participants that experienced olfactory dysfunction; the bivariate analyses showed that there were no significant differences in symptoms/experience between males and females as well as across the age groups. This suggests that both sex and age were not associated with the outcome i.e. olfactory dysfunction or sub- type Of those who had olfactory dysfunction 11/35 were smokers. Only 2 patients experienced blocked nose, of which only one had OD.

The median time to diagnosis for all patients was 5 days. 6 had OD as initial symptom, of which the time to diagnosis was a median of 3 days and an average of 6 days. Of those that had OD, 20 had dysgeusia.

The overall median time to recovery (return of smell) was 7 days (IQR: 4-14-range) Four patients were unavailable for follow-up Tables 2, 3, 4.

There were no significant differences in median time to recovery between males and females or across age groups. This suggests that both sex and age were not associated with the outcome i.e. olfactory dysfunction or sub- type.

Of the 51 patients who did not have OD, 13 were followed up and had no new olfactory dysfunction symptoms at 6 weeks after discharge. Thirty-eight patients could not be reached for follow up.

\section{Discussion}

Our prevalence $(40.7 \%)$ of OD is consistent with the findings of reviews by both Agyeman et al. (41\%) and Qiu et al. $(47 \%)[5,7]$. This figure is essentially representative 
Table 1 Baseline demographic and clinical characteristics

\begin{tabular}{|c|c|c|c|c|}
\hline Variable $^{*}$ & Total $(\mathrm{N}=86)$ & $\begin{array}{l}\text { Olfactory dysfunction } \\
\text { absent }(\mathrm{n}=51)\end{array}$ & $\begin{array}{l}\text { Olfactory dysfunction } \\
\text { present }(\mathrm{n}=35)\end{array}$ & $P$ value \\
\hline Age (Years) & & & & 0.084 \\
\hline Median age & $\begin{array}{l}48.5 \\
\quad(36.0-60.0)\end{array}$ & $46.0(33.0-56.0)$ & $53.0(41.0-64.0)$ & 0.107 \\
\hline$<30$ & $13(15.1 \%)$ & $10(19.6 \%)$ & $3(8.6 \%)$ & \\
\hline $30-<40$ & $13(15.1 \%)$ & $9(17.7 \%)$ & $4(11.4 \%)$ & \\
\hline $40-<50$ & $19(22.1 \%)$ & $9(17.7 \%)$ & $10(28.6 \%)$ & \\
\hline $50-<60$ & $17(19.8 \%)$ & $13(25.5 \%)$ & $4(11.4 \%)$ & \\
\hline$\geq 60$ & $24(27.9 \%)$ & $10(19.6 \%)$ & $14(40.0 \%)$ & \\
\hline Gender & & & & 0.107 \\
\hline Female & $33(38.4 \%)$ & $16(31.4 \%)$ & $17(48.5 \%)$ & \\
\hline Male & $53(61.6 \%)$ & $35(68.6 \%)$ & $18(51.4 \%)$ & \\
\hline Ethnicity & & & & 0.308 \\
\hline African & $83(96.5 \%)$ & $49(96.1 \%)$ & $34(97.1 \%)$ & \\
\hline Coloured & $2(2.3 \%)$ & $2(3.9 \%)$ & $0(0.0 \%)$ & \\
\hline Indian & $1(1.2 \%)$ & $0(0.0 \%)$ & $1(2.9 \%)$ & \\
\hline \multicolumn{5}{|l|}{ Initial symptoms reported } \\
\hline Asymptomatic & $5(5.8 \%)$ & $4(7.8 \%)$ & $1(2.9 \%)$ & 0.644 \\
\hline Headache & $7(8.1 \%)$ & $5(9.8 \%)$ & $2(5.7 \%)$ & 0.696 \\
\hline Fever & $21(21.4 \%)$ & $8(15.7 \%)$ & $13(37.1 \%)$ & 0.039 \\
\hline Body ache & $6(7.0 \%)$ & $3(5.9 \%)$ & $3(8.9 \%)$ & 0.684 \\
\hline Runny nose & $0(0.0 \%)$ & $0(0.0 \%)$ & $0(0.0 \%)$ & - \\
\hline Blocked nose & $5(5.8 \%)$ & $2(3.9 \%)$ & $3(8.6 \%)$ & 0.393 \\
\hline Loss of taste & $10(11.6 \%)$ & $4(7.8 \%)$ & $6(17.1 \%)$ & 0.304 \\
\hline Cough & $18(20.9 \%)$ & $10(19.6 \%)$ & $8(22.9 \%)$ & 0.716 \\
\hline Sore throat & $7(8.1 \%)$ & $5(9.8 \%)$ & $2(5.7 \%)$ & 0.696 \\
\hline Vomiting & $6(7.0 \%)$ & $4(7.8 \%)$ & $2(5.7 \%)$ & 1.000 \\
\hline Shortness of breath & $5(5.8 \%)$ & $3(5.9 \%)$ & $2(5.7 \%)$ & 0.975 \\
\hline Loss of appetite & $1(1.2 \%)$ & $1(2.0 \%)$ & $0(0.0 \%)$ & 1.000 \\
\hline Diarrhoea & $2(2.3 \%)$ & $2(3.0 \%)$ & $0(0.0 \%)$ & 0.512 \\
\hline Hearing loss & $1(1.2 \%)$ & $1(2.0 \%)$ & $0(0.0 \%)$ & 0.593 \\
\hline No of days from symptoms to diagnosis & & & & 0.288 \\
\hline Median time & $5.0(2.0-8.0)$ & $5.0(2.0-8.0)$ & $4.0(2.0-10.0)$ & 0.784 \\
\hline$<5$ days & $28(32.6 \%)$ & $14(27.5 \%)$ & $14(40.0 \%)$ & \\
\hline $5-<10$ & $18(20.9 \%)$ & $12(23.5 \%)$ & $6(17.1 \%)$ & \\
\hline $10-<20$ & $8(9.3 \%)$ & $3(5.9 \%)$ & $5(14.3 \%)$ & \\
\hline$\geq 20$ & $4(4.7 \%)$ & $2(3.9 \%)$ & $2(5.7 \%)$ & \\
\hline Missing & $28(32.6 \%)$ & $20(39.2 \%)$ & $8(22.9 \%)$ & \\
\hline Had blocked nose/discharge from nose & & & & 0.393 \\
\hline No & $81(94.2 \%)$ & $49(96.1 \%)$ & $32(91.4 \%)$ & \\
\hline Yes & $5(5.8 \%)$ & $2(3.9 \%)$ & $3(8.6 \%)$ & \\
\hline Receiving medication for hypertension & & & & 0.091 \\
\hline No & $58(67.4 \%)$ & $38(74.59 \%)$ & $20(57.1 \%)$ & \\
\hline Yes & $28(32.6 \%)$ & $13(25.5 \%)$ & $15(42.9 \%)$ & \\
\hline Receiving medication for diabetes & & & & 0.716 \\
\hline No & $56(65.1 \%)$ & $34(66.7 \%)$ & $22(62.9 \%)$ & \\
\hline Yes & $30(34.9 \%)$ & $17(33.3 \%)$ & $13(37.1 \%)$ & \\
\hline $\begin{array}{l}\text { Receiving medication for } \\
\text { hypothyroidism }\end{array}$ & & & & 0.157 \\
\hline
\end{tabular}


Table 1

\begin{tabular}{llll}
\hline No & $83(96.5 \%)$ & $51(100.0 \%)$ & $32(91.4 \%)$ \\
Yes & $2(2.3 \%)$ & $0(0.0 \%)$ & $2(5.9 \%)$ \\
Missing & $1(1.2 \%)$ & $0(0.0 \%)$ & $1(2.9 \%)$ \\
Smoking status & & & $23(65.7 \%)$ \\
Non smoker & $61(70.9 \%)$ & $38(74.5 \%)$ & $12(32.3 \%)$ \\
Smoker & $25(29.1 \%)$ & $13(25.5 \%)$ & 0.348 \\
\hline
\end{tabular}

*Percentages may not add up to $100 \%$ due to rounding off

of the prevalence in Black Africans in our setting, as they comprised $97 \%$ of the study population. A study in Somalia shows similar prevalence of $40 \%$ [22]. The prevalence may be an underestimate since OD has a higher prevalence in outpatients and mild disease and our study sample was hospital based [10, 23, 24].

OD is a common feature of aging and has been documented in approximately $75 \%$ of patients older than 80 years [25]. In COVID-19 however OD is more prevalent in younger age groups [5]. We did not demonstrate any significant differences amongst our various age groups, possibly an effect of the small numbers in each sub-group. In this study there was no difference in the occurrence of OD between males and females. Previous research on the role of gender in patients with OD has been inconsistent. The review by Agyeman et al. found no difference in the frequency of OD between genders however Saniasiaya et al. showed a female predominance of $61 \%$ [5, 17]. A significant finding in the study was the higher number of female patients with co-morbidities (diabetes and hypertension). This is consistent with a recently published study examining infectious and non-communicable diseases which concluded that women bear a significant burden of disease in South Africa [26].

We identified the presence of OD as the initial symptom in $6(7 \%)$ patients. This figure is similar to that reported previously (2.9\%) by Speth et al. [6]. A recent systematic review concluded that OD occurs early during the course of the disease but was the initial symptom in only a minority of cases [6]. Studies comparing the prevalence of OD have documented underreporting in subjective studies such as ours [27]. In our study only $48.5 \%$ reported the OD to be a bother to them.

The overall median recovery time in our study was 7 days. A recent systematic review noted that most studies reported a resolution of OD within 14 days of symptom onset [28]. Recovery rates vary considerably as noted by Salamanna et al. [28]. In their review it varied between 5 and $50 \%$. A noteworthy finding in the review was a relative dearth of information in patients with moderate-severe disease, which our sample represents. During the 6 week follow-up period only 1 (3\%) patient did not recover from their OD. In a study by Lechien et al., $15.3 \%$ of patients with anosmia did not recover at 6 months [24]. Our study focused on acute OD and therefore we only followed up patients for 6 weeks. It would be of interest in future studies to note if patients who recover their sense of smell, would later develop cacosmia.

Dysgeusia was documented in $10(11.6 \%)$ of our patients. This figure is significantly lower than the pooled prevalence $(36.6 \%)$ reported in the meta-analysis by Mutiawati et al. [29]. The prevalence in the 16 studies included in their meta-analysis varied between 2.8 and $76.6 \%$. Geographical variations in COVID-19 associated dysgeusia have been noted previously [30]. A previous study from Africa found dysgeusia in $23.3 \%$ of patients [22].

\section{Conclusion}

From our sample of 86 patients admitted at a tertiary hospital with SARS-COV-2, 35 presented with olfactory dysfunction representing a prevalence of $40.7 \%$. The only clinical characteristic that was significant between patients with OD and those without was the presence of fever i.e. a higher proportion of patients with olfactory dysfunction had fever compared to those without.

Prevalence of OD in our population is in keeping with European studies and most patients recover their sense of smell within a week.

Our study confirms findings of previous studies and further addresses existing knowledge gaps regarding olfactory and gustatory dysfunction in COVID-19 patients in Africa. The prevalence of OD in our hospital based population is consistent with published data, but the 
Table 2 Demographic and clinical characteristics at baseline stratified by sex

\begin{tabular}{|c|c|c|c|c|}
\hline Variable $^{*}$ & Total $(\mathrm{n}=86)$ & Female $(\mathrm{n}=33)$ & Male $(\mathrm{n}=53)$ & $P$ value \\
\hline Age (Years) & & & & 0.738 \\
\hline Median age & $48.5(36.0-60.0)$ & $51.0(40.0-62.0)$ & $45.0(36.0-59.0)$ & 0.320 \\
\hline$<30$ & $13(15.1 \%)$ & $4(12.1 \%)$ & $9(17.0 \%)$ & \\
\hline $30-<40$ & $13(15.1 \%)$ & $4(12.1 \%)$ & $9(17.0 \%)$ & \\
\hline $40-<50$ & $19(22.1 \%)$ & $6(18.2 \%)$ & $13(24.5 \%)$ & \\
\hline $50-<60$ & $17(19.8 \%)$ & $8(24.2 \%)$ & $9(17.0 \%)$ & \\
\hline$\geq 60$ & $24(27.9 \%)$ & $11(33.3 \%)$ & $13(24.5 \%)$ & \\
\hline Ethnicity & & & & 1.000 \\
\hline African & $83(96.5 \%)$ & $32(97.0 \%)$ & $51(96.2 \%)$ & \\
\hline Coloured & $2(2.3 \%)$ & $1(3.0 \%)$ & $1(1.9 \%)$ & \\
\hline Indian & $1(1.2 \%)$ & $0(0.0 \%)$ & $1(1.9 \%)$ & \\
\hline \multicolumn{5}{|l|}{ Initial symptoms reported } \\
\hline Asymptomatic & $5(5.8 \%)$ & $2(6.1 \%)$ & $3(5.7 \%)$ & 0.939 \\
\hline Headache & $7(8.1 \%)$ & $3(9.1 \%)$ & $4(7.6 \%)$ & 0.799 \\
\hline Fever & $21(21.4 \%)$ & $10(30.3 \%)$ & $11(20.8 \%)$ & 0.439 \\
\hline Body ache & $6(7.0 \%)$ & $2(6.1 \%)$ & $4(7.6 \%)$ & 1.000 \\
\hline Runny nose & $0(0.0 \%)$ & $0(0.0 \%)$ & $0(0.0 \%)$ & - \\
\hline Blocked nose & $5(5.8 \%)$ & $3(9.1 \%)$ & $2(3.8 \%)$ & 0.367 \\
\hline Loss of taste & $10(11.6 \%)$ & $5(15.2 \%)$ & $5(9.4 \%)$ & 0.497 \\
\hline Cough & $18(20.9 \%)$ & $8(24.2 \%)$ & $10(18.9 \%)$ & 0.593 \\
\hline Sore throat & $7(8.1 \%)$ & $3(9.1 \%)$ & $4(7.6 \%)$ & 1.000 \\
\hline Vomiting & $6(7.0 \%)$ & $3(9.1 \%)$ & $3(5.7 \%)$ & 0.671 \\
\hline Shortness of breath & $5(5.8 \%)$ & $0(0.0 \%)$ & $5(9.4 \%)$ & 0.069 \\
\hline Loss of appetite & $1(1.2 \%)$ & $0(0.0 \%)$ & $1(1.9 \%)$ & 1.000 \\
\hline Diarrhoea & $2(2.3 \%)$ & $2(6.1 \%)$ & $0(0.0 \%)$ & 0.144 \\
\hline Hearing loss & $1(1.2 \%)$ & $1(3.0 \%)$ & $0(0.0 \%)$ & 0.384 \\
\hline No of days from symptoms to diagnosis & & & & 0.872 \\
\hline Median time & $5.0(2.0-8.0)$ & $6.0(3.0-8.0)$ & $4.0(2.0-8.0)$ & 0.329 \\
\hline$<5$ days & $28(32.6 \%)$ & $9(27.3 \%)$ & $19(35.9 \%)$ & \\
\hline $5-<10$ & $18(20.9 \%)$ & $8(24.2 \%)$ & $10(18.9 \%)$ & \\
\hline $10-<20$ & $8(9.3 \%)$ & $3(9.1 \%)$ & $5(9.4 \%)$ & \\
\hline$\geq 20$ & $4(4.7 \%)$ & $1(3.0 \%)$ & $3(5.7 \%)$ & \\
\hline Missing & $28(32.6 \%)$ & $12(36.4 \%)$ & $16(30.2 \%)$ & \\
\hline Reported change in sense of smell during current SARS COV-2 infection & & & & 0.107 \\
\hline No & $51(59.3 \%)$ & $16(48.5 \%)$ & $35(66.0 \%)$ & \\
\hline Yes & $35(40.7 \%)$ & $17(51.5 \%)$ & $18(34.0 \%)$ & \\
\hline Had blocked nose/discharge from nose & & & & 0.521 \\
\hline No & $81(94.2 \%)$ & $30(90.9 \%)$ & $51(96.2 \%)$ & \\
\hline Yes & $5(5.8 \%)$ & $3(9.1 \%)$ & $2(3.8 \%)$ & \\
\hline Receiving medication for hypertension & & & & 0.018 \\
\hline No & $58(67.4 \%)$ & $17(51.5 \%)$ & $41(77.4 \%)$ & \\
\hline Yes & $28(32.6 \%)$ & $16(48.5 \%)$ & $12(22.6 \%)$ & \\
\hline Receiving medication for diabetes & & & & $\mathbf{0 . 0 3 7}$ \\
\hline No & $56(65.1 \%)$ & $17(51.5 \%)$ & $39(73.6 \%)$ & \\
\hline Yes & $30(34.9 \%)$ & $16(48.5 \%)$ & $14(26.4 \%)$ & \\
\hline Receiving medication for hypothyroidism & & & & 0.139 \\
\hline No & $83(96.5 \%)$ & $30(90.9 \%)$ & $53(100.0 \%)$ & \\
\hline Yes & $2(2.3 \%)$ & $2(6.1 \%)$ & $0(0.0 \%)$ & \\
\hline
\end{tabular}


Table 2

\begin{tabular}{lccc}
\hline Missing & $1(1.2 \%)$ & $1(3.0 \%)$ & $0(0.0 \%)$ \\
Smoking status & & & 0.205 \\
Non smoker & $61(70.9 \%)$ & $26(78.8 \%)$ & $35(66.0 \%)$ \\
Smoker & $25(29.1 \%)$ & $7(21.2 \%)$ & $18(34.0 \%)$ \\
\hline
\end{tabular}

*Percentages may not add up due to rounding off

Table 3 Baseline demographic and clinical characteristics stratified by age

\begin{tabular}{|c|c|c|c|c|c|c|c|}
\hline \multirow[t]{2}{*}{ Variable } & \multirow{2}{*}{$\begin{array}{l}\text { Total } \\
(\mathrm{n}=86)\end{array}$} & \multicolumn{5}{|c|}{ Age group (Years) } & \multirow[b]{2}{*}{$P$ value } \\
\hline & & $\begin{array}{l}<30 \\
(\mathrm{n}=13)\end{array}$ & $\begin{array}{l}30-<40 \\
(\mathrm{n}=13)\end{array}$ & $\begin{array}{l}40-<50 \\
(\mathrm{n}=19)\end{array}$ & $\begin{array}{l}50-<60 \\
(\mathrm{n}=17)\end{array}$ & $\begin{array}{l}\geq 60 \\
(\mathrm{n}=24)\end{array}$ & \\
\hline \multicolumn{8}{|c|}{ Reported change in sense of smell during current SARS COV-2 infection } \\
\hline No & $51(59.3 \%)$ & $10(76.9 \%)$ & $9(69.2 \%)$ & $9(47.4 \%)$ & $13(76.5 \%)$ & $10(41.7 \%)$ & 0.084 \\
\hline Yes & $35(40.7 \%)$ & $3(23.1 \%)$ & $8(30.8 \%)$ & $10(52.6 \%)$ & $4(23.5 \%)$ & $14(58.3 \%)$ & \\
\hline \multicolumn{8}{|l|}{ Initial symptoms reported } \\
\hline Asymptomatic & $5(5.8 \%)$ & $0(0.0 \%)$ & $0(0.0 \%)$ & $1(5.3 \%)$ & $1(5.9 \%)$ & $3(12.5 \%)$ & 0.686 \\
\hline Headache & $7(8.1 \%)$ & $1(7.7 \%)$ & $1(7.7 \%)$ & $3(15.8 \%)$ & $1(5.9 \%)$ & $1(4.2 \%)$ & 0.769 \\
\hline Fever & $21(21.4 \%)$ & $4(30.8 \%)$ & $2(15.4 \%)$ & $6(31.6 \%)$ & $5(29.4 \%)$ & $4(16.7 \%)$ & 0.666 \\
\hline Loss of smell & $6(7.0 \%)$ & $1(7.7 \%)$ & $1(7.7 \%)$ & $1(5.3 \%)$ & $1(5.9 \%)$ & $2(8.3 \%)$ & 1.000 \\
\hline Body ache & $6(7.0 \%)$ & $2(15.4 \%)$ & $1(7.7 \%)$ & $1(5.3 \%)$ & $0(0.0 \%)$ & $2(8.3 \%)$ & 0.601 \\
\hline Blocked nose & $5(5.8 \%)$ & $0(0.0 \%)$ & $2(15.4 \%)$ & $2(10.5 \%)$ & $1(5.9 \%)$ & $0(0.0 \%)$ & 0.203 \\
\hline Loss of taste & $10(11.6 \%)$ & $4(30.8 \%)$ & $1(7.7 \%)$ & $2(10.5 \%)$ & $0(0.0 \%)$ & $3(12.5 \%)$ & 0.147 \\
\hline Cough & $18(20.9 \%)$ & $3(23.1 \%)$ & $1(7.7 \%)$ & $4(21.1 \%)$ & $8(47.1 \%$ & $2(8.3 \%)$ & 0.038 \\
\hline Sore throat & $7(8.1 \%)$ & $2(15.4 \%)$ & $1(7.7 \%)$ & $2(10.5 \%)$ & $1(5.9 \%)$ & $1(4.2 \%)$ & 0.821 \\
\hline Vomiting & $6(7.0 \%)$ & $0(0.0 \%)$ & $1(7.7 \%)$ & $2(10.5 \%)$ & $2(11.8 \%)$ & $1(4.2 \%)$ & 0.691 \\
\hline Shortness of breath & $5(5.8 \%)$ & $0(0.0 \%)$ & $1(7.7 \%)$ & $0(0.0 \%)$ & $2(11.8 \%)$ & $2(8.3 \%)$ & 0.522 \\
\hline Loss of appetite & $1(1.2 \%)$ & $0(0.0 \%)$ & $0(0.0 \%)$ & $1(5.3 \%)$ & $0(0.0 \%)$ & $0(0.0 \%)$ & 0.721 \\
\hline Diarrhoea & $2(2.3 \%)$ & $0(0.0 \%)$ & $1(7.7 \%)$ & $0(0.0 \%)$ & $1(5.9 \%)$ & $0(0.0 \%)$ & 0.294 \\
\hline Hearing loss & $1(1.2 \%)$ & $0(0.0 \%)$ & $1(7.7 \%)$ & $0(0.0 \%)$ & $1(5.9 \%)$ & $0(0.0 \%)$ & 0.294 \\
\hline $\begin{array}{l}\text { No of days from symptoms to } \\
\text { diagnosis }\end{array}$ & & & & & & & 0.938 \\
\hline Median time & $5.0(2.0-8.0)$ & $3.0(2.0-5.0)$ & $6.5(2.5-9.0)$ & $5.0(2.0-15.0)$ & $4.0(1.0-8.0)$ & $\begin{array}{l}5.0 \\
\quad(2.0-10.0)\end{array}$ & 0.803 \\
\hline$<5$ days & $28(32.6 \%)$ & $5(38.5 \%)$ & $3(23.1 \%)$ & $6(31.6 \%)$ & $7(41.2 \%)$ & $7(29.2 \%)$ & \\
\hline $5-<10$ & $18(20.9 \%)$ & $2(15.4 \%)$ & $3(23.1 \%)$ & $5(26.3 \%)$ & $4(23.5 \%)$ & $4(16.7 \%)$ & \\
\hline $10-<20$ & $8(9.3 \%)$ & $1(7.7 \%)$ & $2(15.4 \%)$ & $1(5.3 \%)$ & $1(5.9 \%)$ & $3(12.5 \%)$ & \\
\hline$\geq 20$ & $4(4.7 \%)$ & $0(0.0 \%)$ & $0(0.0 \%)$ & $3(15.8 \%)$ & $0(0.0 \%)$ & $1(4.2 \%)$ & \\
\hline Missing & $28(32.6 \%)$ & $5(38.5 \%)$ & $5(38.5 \%)$ & $4(21.1 \%)$ & $5(29.4 \%)$ & $9(37.5 \%)$ & \\
\hline
\end{tabular}

*Percentages may not add up due to rounding off 
Table 4 Experiences of olfactory dysfunction

\begin{tabular}{|c|c|c|c|c|c|c|c|c|c|c|}
\hline \multirow[t]{2}{*}{ Variable } & \multicolumn{4}{|l|}{ Gender } & \multicolumn{5}{|c|}{ Age group (Years) } & \multirow[t]{2}{*}{$P$ value } \\
\hline & $\begin{array}{l}\text { Total } \\
(\mathrm{n}=35)\end{array}$ & $\begin{array}{l}\text { Females } \\
(\mathrm{n}=17)\end{array}$ & $\begin{array}{l}\text { Males } \\
(\mathrm{n}=18)\end{array}$ & $\begin{array}{l}\mathrm{P} \\
\text { value }\end{array}$ & $\begin{array}{l}<30 \\
(\mathrm{n}=3)\end{array}$ & $\begin{array}{l}30-<40 \\
(\mathrm{n}=4)\end{array}$ & $\begin{array}{l}40-<50 \\
(\mathrm{n}=10)\end{array}$ & $\begin{array}{l}\geq 55 \\
(\mathrm{n}=4)\end{array}$ & $\begin{array}{l}\geq 60 \\
(\mathrm{n}=14)\end{array}$ & \\
\hline Complete loss of smell & & & & 0.939 & & & & & & 0.724 \\
\hline No & 29 (82.9\%) & $14(82.4 \%)$ & $\begin{array}{l}15 \\
(83.3 \%)\end{array}$ & & $2(66.7 \%)$ & $3(75.0 \%)$ & $9(90.0 \%)$ & $12(85.7 \%)$ & $3(23.1 \%)$ & \\
\hline Yes & $6(17.1 \%)$ & $3(17.7 \%)$ & $3(16.7 \%)$ & & $1(33.3 \%)$ & $1(25.0 \%)$ & $110.0 \%)$ & $2(14.3 \%)$ & $\begin{array}{l}10 \\
(76.9 \%)\end{array}$ & \\
\hline$\downarrow$ sense of smell & & & & 0.863 & & & & & & 0.107 \\
\hline No & $9(25.7 \%)$ & $4(23.5 \%)$ & $5(27.8 \%)$ & & $2(66.7 \%)$ & $0(0.0 \%)$ & $4(40.0 \%)$ & $0(0.0 \%)$ & $3(21.4 \%)$ & \\
\hline Yes & $23(65.7 \%)$ & $11(64.7 \%)$ & ${ }^{12}(66.7 \%)$ & & $0(0.0 \%)$ & $3(75.0 \%)$ & $6(60.0 \%)$ & $4(100.0 \%)$ & $\begin{array}{l}10 \\
(71.4 \%)\end{array}$ & \\
\hline Data unavailable & $3(8.6 \%)$ & $2(11.7 \%)$ & $1(5.5 \%)$ & & $1(33.3 \%)$ & $1(25.0 \%)$ & $0(0.0 \%)$ & $0(0.0 \%)$ & $1(7.1 \%)$ & \\
\hline $\begin{array}{l}\downarrow \text { sense of smell affects } \\
\text { daily activities }\end{array}$ & & & & 1.000 & & & & & & 0.411 \\
\hline No & $\begin{array}{l}29 \\
(82.9 \%)\end{array}$ & $14(82.4 \%)$ & $\begin{array}{l}15 \\
(83.3 \%)\end{array}$ & & $1(33.3 \%)$ & $3(75.0 \%)$ & $9(90.0 \%)$ & $4(100.0 \%)$ & ${ }^{12}(85.7 \%)$ & \\
\hline Yes & $6(17.1 \%)$ & $3(17.6 \%)$ & $3(16.7 \%)$ & & $2(66.7 \%)$ & $1(25.0 \%)$ & $1(10.0 \%)$ & $0(0.0 \%)$ & $2(14.3)$ & \\
\hline $\begin{array}{l}\downarrow \text { sense of smell affects } \\
\text { taste }\end{array}$ & & & & 0.225 & & & & & & 0.738 \\
\hline No & $8(22.9 \%)$ & $2(11.8 \%)$ & $6(33.3 \%)$ & & $0(0.0 \%)$ & $2(50.0 \%)$ & $2(20.0 \%)$ & $1(25.0 \%)$ & $3(21.4 \%)$ & \\
\hline Yes & 26 (74.3\%) & $15(88.2 \%)$ & ${ }^{11}(61.1 \%)$ & & $3100.0 \%)$ & $2(50.0 \%)$ & $8(80.0 \%)$ & $3(75.0 \%)$ & $\begin{array}{l}10 \\
(71.4 \%)\end{array}$ & \\
\hline Data unavailable & $1(2.9 \%)$ & $0(0.0 \%)$ & $1(5.6 \%)$ & & $0(0.0 \%)$ & $0(0.0 \%)$ & $0(0.0 \%)$ & $0(0.0 \%)$ & $1(7.1 \%)$ & \\
\hline $\begin{array}{l}\downarrow \text { sense of smell bothers } \\
\text { me }\end{array}$ & & & & 1.000 & & & & & & 0.257 \\
\hline No & ${ }^{17}(48.6 \%)$ & $9(52.9 \%)$ & $8(44.4 \%)$ & & $0(0.0 \%)$ & $2(50.0 \%)$ & $5(50.0 \%)$ & $1(25.0 \%)$ & $9(64.3 \%)$ & \\
\hline Yes & $\begin{array}{l}17(48.6 \%) \\
\end{array}$ & $8(47.1 \%)$ & $9(50.0 \%)$ & & $3100.0 \%)$ & $2(50.0 \%)$ & $5(50.0 \%)$ & $3(75.0 \%)$ & $4(28.6 \%)$ & \\
\hline Data unavailable & $1(2.9 \%)$ & $0(0.0 \%)$ & $1(5.6 \%)$ & & $0(0.0 \%)$ & $0(0.0 \%)$ & $0(0.0 \%)$ & $0(0.0 \%)$ & $1(7.1 \%)$ & \\
\hline Sense of smell returned & & & & 0.485 & & & & & & 0.811 \\
\hline $\begin{array}{l}\text { Median time to recovery } \\
\text { (Days) }\end{array}$ & $7(4-14)$ & $12(4-21)$ & $5(2.5-11)$ & 0.158 & $7(2-48)$ & $\begin{array}{l}12.5 \\
(3.5-21)\end{array}$ & $6.5(4-12)$ & $4.5(2-18)$ & $11(4-14)$ & \\
\hline No & $1(2.9 \%)$ & $0(0.0 \%)$ & $1(5.6 \%)$ & & $0(0.0 \%)$ & $0(0.0 \%)$ & $0(0.0 \%)$ & $0(11.1 \%)$ & $1(7.1 \%)$ & \\
\hline Yes & 32 (91.4\%) & $\left.{ }^{17} 100.0 \%\right)$ & ${ }^{15}(83.3 \%)$ & & $3100.0 \%)$ & $3(75.0 \%)$ & $10(100.0 \%)$ & $4(100.0 \%)$ & ${ }^{12}(85.7 \%)$ & \\
\hline Data unavailable & $2(5.7 \%)$ & $0(0.0 \%)$ & $2(11.1 \%)$ & & $0(0.0 \%)$ & $1(25.0 \%)$ & $0(0.0 \%)$ & $0(0.0 \%)$ & $1(7.1 \%)$ & \\
\hline
\end{tabular}

documented rate and speed of recovery of OD in this study has no obvious explanation. The limitations of the study are mainly our ascertainment bias, cohort size and the reliability on adequate patient recall and reporting.

Funding No research grant was utilized for the study conducted.

\section{Declarations}

Conflict of interest The authors hereby declare that they have no conflict of interest.
Ethical Approval All procedures performed in this study involving human participants were conducted in accordance with the ethical standards of the Helsinki guidelines. Ethics approval was granted by the human research and ethics committee, University of the Witwatersrand.

\section{References}

1. Adetuyi BO, Olajide PA, Awoyelu EH, Adetuyi OA, Adebisi OA, Oloke JK (2020) Epidemiology and treatment options for COVID-19: a review. Afr J Reprod Health 24(2):142-153 
2. First Case Of Covid-19 Coronavirus Reported In SA [Internet]. 2020 [cited 5 MARCH 2020]. Available from: https://www. nicd.ac.za/first-case-of-covid-19-coronavirus-reported-in-sa/.

3. Latest Confirmed Cases Of Covid-19 In South Africa (8 JULY 2020) [Internet]. NICD. 2020. Available from: https://www. nicd.ac.za/latest-confirmed-cases-of-covid-19-in-south-africa-8july-2020/.

4. Lovato A, de Filippis C (2020) Clinical presentation of Covid-19: a systematic review focusing on upper airway symptoms. Ear Nose Throat J 99(9):569-576

5. Agyeman AA , Chin KL, Landersdorfer CB, Liew D, OforiAsenso R (2020) Smell and taste dysfunction in patients With COVID-19: a systematic review and meta-analysis. Mayo Clin Proc 95(8):1621-1631

6. Speth MM, Singer-Cornelius T, Oberle M, Gengler I, Brockmeier SJ, Sedaghat AR (2020) covid19 Olfactory dysfunction and sinonasal symptomatology in COVID-19: prevalence, severity, timing, and associated characteristics. Otolaryngol-Head Neck Surg 163(1):114-120

7. Qiu J, Yang X, Liu L, Wu T, Cui L, Mou Y, Sun Y (2001) Prevalence and prognosis of otorhinolaryngological symptoms in patients with COVID-19: a systematic review and meta-analysis. Eur Arch Otorhinolaryngol. https://doi.org/10.1007/s00405021-06900-8

8. Mullol J , Alobid I, Marino-Sanchez F , Izquierdo-Dominguez A, Marin C, Klimek L (2020) The loss of smell and taste in the COVID-19 outbreak: a tale of many countries. Curr Allergy Asthma Rep 20:10-61

9. Zayet S, Klopfenstein T, Mercier J, Kadiane-Oussou NJ, Lan Cheong Wah L, Royer PY, et al. (2020) Contribution of anosmia and dysgeusia for diagnostic of COVID-19 in outpatients. Infection

10. Yan CH, Faraji F, Prajapati DP, Boone CE, DeConde AS (2020) Association of chemosensory dysfunction and COVID-19 in patients presenting with influenza-like symptoms. Int Forum Allergy Rhinol 10(7):806-813

11. Vaira LA, Deiana G, Fois AG, Pirina P, Madeddu G, Vito De A (2020) Objective evaluation of anosmia and ageusia in COVID19 patients: single-center experience on 72 cases. Head Neck 42(6):1252-1258

12. Lechien JR, Chiesa-Estomba CM, Siati De DR, Horoi M, Bon Le SD, Rodriguez A (2020) Olfactory and gustatory dysfunctions as a clinical presentation of mild-to-moderate forms of the coronavirus disease (COVID-19): a multicenter European study. Eur Arch Otorhinolaryngol 277(8):2251-2261

13. Kaye R, Chang CWD, Kazahaya K, Brereton J, Denneny JC (2020) COVID-19 anosmia reporting tool: initial findings. Otolaryngol Head Neck Surg 163(1):132-134

14. Lee Y, Min P, Lee S, Kim SW (2020) Prevalence and duration of acute loss of smell or taste in COVID-19 patients. J Korean Med Sci 35(18):e174

15. El-Anwar MW, Elzayat S, Fouad YA (2020) ENT manifestation in COVID-19 patients. Auris Nasus Larynx 47(4):559-564

16. Sahoo PR, Sahu M, Surapaneni PS, Maiti A, Vankamamidi R, Panda N, et al. (2021) Evolution of olfactory and gustatory dysfunctions in COVID-19 patients in India. European Archives of Oto-Rhino-Laryngology. 2021:1-7
17. Saniasiaya J , Islam MA, Abdullah B (2021) Prevalence of olfactory dysfunction in coronavirus disease 2019 (COVID-19): a meta-analysis of 27,492 patients. Laryngoscope 131(4):865-878

18. Bartheld von CS, Hagen MM, Butowt R (2020) Prevalence of chemosensory dysfunction in COVID-19 patients: a systematic review and meta-analysis reveals significant ethnic differences. ACS Chem Neurosci 11(19):2944-2961

19. Butowt R, Bilinska K, Bartheld Von CS (2020) Chemosensory dysfunction in COVID-19: integration of genetic and epidemiological data points to D614G spike protein variant as a contributing factor. ACS Chem Neurosci 11(20):3180-3184

20. Mann NM, Lafreniere D (2004) Anosmia and nasal sinus disease. Otolaryngol Clin North Am 37(2):289-300

21. Hopkins C, Surda P, Whitehead E, Kumar BN (2020) Early recovery following new onset anosmia during the COVID-19 pandemic - an observational cohort study. J Otolaryngol Head Neck Surg 49:1-26

22. Farah Yusuf Mohamud M, Garad Mohamed Y, Mohamed Ali A, Adam BA (2020) Loss of taste and smell are common clinical characteristics of patients with COVID-19 in Somalia: a retrospective double centre study. Infect Drug Resist 13:2631-2635

23. Hopkins C, Lechien JR, Saussez S (2021) More that ACE2? NRP1 may play a central role in the underlying pathophysiological mechanism of olfactory dysfunction in COVID-19 and its association with enhanced survival. Med Hypotheses 146:110406

24. Lechien J, Chiesa-Estomba CM, Beckers E, Mustin V, Ducarme M, Journe F (2021) Prevalence and 6-month recovery of olfactory dysfunction: a multicentre study of 1363 COVID-19 patients. J Intern Med 290(2):451-461

25. Boyce JM, Shone GR (2006) Effects of ageing on smell and taste. Postgrad Med J 82(966):239-241

26. Doyel L, Hoffman M (2009) The growing burden of chronic diseases among South African women. Contin Med Educ 27(10):456-458

27. Rajkumar I, Anand KH, Revathishree K, Shoba K, Srinivasan K (2020) Contemporary analysis of olfactory dysfunction in mild to moderate Covid 19 patients in a tertiary health care centre. Indian J Otolaryngol Head Neck Surg https://doi.org/10.1007/s 12070-020-02175-3

28. Salamanna F, Veronesi F, Martini L, Landini MP, Fini M (2021) Post-COVID-19 syndrome: the persistent Symptoms at the postviral stage of the disease a systematic review of the current data. Front Med 8:392

29. Mutiawati E, Fahriani M, Mamada SS, Fajar JK, Frediansyah A, Maliga HA 2021 Anosmia and dysgeusia in SARS-CoV-2 infection incidence and effects on COVID-19 severity and mortality and the possible pathobiology mechanisms - a systematic review and meta-analysis. F1000Res 10:40

30. Cirillo N, Bizzoca ME, Lo Muzio E, Cazzolla AP, Lo Muzio LL (2021) Gustatory dysfunction in COVID-19 patients: a rapid systematic review on 27,687 cases. Acta Odontol Scand. https://doi.org/10.1080/00016357.2020.1869828

Publisher's Note Springer Nature remains neutral with regard to jurisdictional claims in published maps and institutional affiliations. 